\title{
Dependence of Adsorptive Capability for Lithium Ions in Molten Salt on Surface Properties of Activated Alumina
}

\author{
Kiyosumi FUJII \\ Kansai Research Center, Technical Research Laboratory, Nippon Sheet Glass Co., Ltd., 1, Kaidoshita, Konoike, Itami-shi, Hyogo 664

\begin{abstract}
溶融塩中リチウムイオン吸着能力に対する活性アルミナの表面特性依存性 藤井清澄

日本板硝子(株)技術研究所関西研究センター, 664 兵庫県伊丹市鴻池字街道下 1 番
\end{abstract}

[Received March 10, 1994; Accepted September 20, 1994]

\begin{abstract}
It was reported in our previous work that activated alu= mina had been successfully applied to selective adsorp= tion of lithium ions in molten $\mathrm{NaNO}_{3}$ at a high tempera= ture. In the present work, the activated alumina samples were prepared by heat treatment of commercially available alumina sol at different temperatures. Their physical properties were measured, then their adsorption uptake of lithium ions were evaluated. Amorphous alumina showed higher adsorption uptake of lithium ions than any other phases of alumina and the uptake increased in proportion to the surface area of activated alumina. The lithium ion uptake per unit surface area varied slightly with the phase of alumina, implying that the surface microstructure of each activated alumina has a different adsorptive capability for lithium ions. Since the mean pore radius of each activated alumina sample was at least forty times larger than the ionic radius of lithium, it may be concluded that there is little effect of the pore size on adsorptive capabilities for lithium ions.
\end{abstract}

Key-words : Activated alumina, Adsorption, Lithium ion, Molten salt, Specific surface area, Pore size distribution

\section{Introduction}

The exchange of lithium ion in glass for sodium ion in molten $\mathrm{NaNO}_{3}$ at around $500^{\circ} \mathrm{C}$ has been widely exploited to produce gradient-index lenses which are applied to imaging lenses for copiers, facsimiles, and printers. ${ }^{1,2)}$

From the industrial point of view, one of the biggest problems in this case is the high cost of the purification of molten salt contaminated with a slight amount of lithium ions diffusing out from the glass through the ion exchange process.

At present, a crystallization method which recovers $\mathrm{NaNO}_{3}$ from a water solution containing molten salt after ion exchange is used as the purification method. However, this method has two disadvantages. One is large electric power loss (evolution of heat energy) because molten salt is cooled when it is dissolved in water at room temperature. The other is large substance loss of $\mathrm{NaNO}_{3}$ because the $\mathrm{NaNO}_{3}$ dissolved in water can not be recovered until saturation. To overcome these difficulties, a new purification method using inorganic adsorbents was studied.

In the previous work, ${ }^{3)}$ activated alumina was successfully applied to selective adsorption of lithium ions in molten $\mathrm{NaNO}_{3}$ at a high temperature. This application appears very promising for the purification of molten $\mathrm{NaNO}_{3}$ on a mass-production scale.

Also, the author reported the type of adsorption of lithium ions by commercially available activated alumina, the stability of activated alumina when mixed with molten salt at a high temperature, and the enrichment of lithium ions on activated alumina. However, the relationship between physical properties and adsorptive capabilities of activated alumina was not clear.

In the present work, the activated alumina samples were prepared by heat treatment of alumina sol at different temperatures, their physical properties were examined by several kinds of analysis and their adsorptive capabilities for lithium ions were evaluated by a batch method. Finally, the relationship between the physical properties and the adsorptive capabilities for lithium ions of the activated alumina samples is discussed.

\section{Experimental}

2.1 Preparation of activated alumina

Commercially available alumina sol (Alumina sol520, Nissan Chemical Industries, Ltd.) was employed as a starting material in this study. The chemical composition of alumina sol analyzed by the supplier is shown in Table 1. A large amount of alumina sol was placed in an oven at $120^{\circ} \mathrm{C}$, dried for about 1 week in air and formed into alumina gel. Then alumina gel of $0.2 \mathrm{~kg}$ was put in an alumina crucible and heated at temperatures in the range from 300 to $900^{\circ} \mathrm{C}$ at $200^{\circ} \mathrm{C}$ intervals, each for $20 \mathrm{~h}$ in a nichrome element furnace in air or heated at $1100^{\circ} \mathrm{C}$ for $6 \mathrm{~h}$ in a silicon carbide furnace in air. Table 2 summarizes the preparation conditions for the activated alumina samples (Sample numbers: a to e). The heat-treated samples were broken into about $2 \mathrm{~mm}$ granules us- 
Table 1. Chemical Analysis of Commercially Available Alumina Sol Used as the Starting Material for Preparing the Activated Alumina Samples

\begin{tabular}{lccc}
\hline Constituent & /mass \% & Impurity & /mass ppm \\
\hline $\mathrm{Al}_{2} \mathrm{O} 3$ & 20.84 & $\mathrm{Na}$ & $\leqq 30$ \\
$\mathrm{NO}^{*}$ & 0.62 & $\mathrm{Fe}$ & $\leqq 20$ \\
$\mathrm{Ti}$ & 0.025 & $\mathrm{~K}$ & $\leqq 10$ \\
$\mathrm{H}_{2} \mathrm{O}^{* *}$ & residue & $\mathrm{Mg}$ & $\leqq 2$ \\
\hline * Stabilizer & ** Disperse medium & &
\end{tabular}

Table 2. Preparation Conditions for the Activated Alumina Samples

\begin{tabular}{ccc}
\hline $\begin{array}{c}\text { Sample } \\
\text { number }\end{array}$ & $\begin{array}{c}\text { Heat treatment } \\
\text { temperature } \\
/{ }^{\circ} \mathrm{C}\end{array}$ & $\begin{array}{c}\text { Heat treatment } \\
\text { time }\end{array}$ \\
\hline $\mathrm{a}$ & 300 & 20 \\
$\mathrm{~b}$ & 500 & 20 \\
$\mathrm{c}$ & 700 & 20 \\
$\mathrm{~d}$ & 900 & 20 \\
$\mathrm{e}$ & 1100 & 6 \\
\hline
\end{tabular}

Note: All samples were dried at $120^{\circ} \mathrm{C}$ for $24 \mathrm{~h}$ in air before heat treatment

ing an alumina mortar and pestle.

\subsection{Characterization of activated alumina}

Differential thermal analysis (DTA) and thermogravimetry (TG) of the alumina sol employed as the starting material were carried out with a Rigaku Denki Thermoflex at a heating rate of $15^{\circ} \mathrm{C}$ per minute to $1200^{\circ} \mathrm{C}$. X-ray diffraction studies on the samples were carried out with a Rigaku Denki RAD$\mathrm{RC}$ diffractometer Rotaflex using Ni-filtered $\mathrm{Cu} \mathrm{K} \alpha$ radiation. BET surface area and pore volume of the samples were measured by Carlo Erba Sorptomatic Model 1800, using nitrogen as an adsorbate at $-196^{\circ} \mathrm{C}$. Pore size distribution was determined by the Barrett, Joyner and Halenda (B.J.H.) method, $\left.{ }^{4}\right)$ assuming the pore shape to be open-ended or cylindrical. Mean pore radius was calculated as the weighted average size from the data of the pore size distribution.

2.3 Adsorption of lithium ions from molten salt

Adsorption of lithium ions from molten salt was examined by the batch method. In the batch method a certain weight of activated alumina was added to about $440 \mathrm{~cm}^{3}$ molten $\mathrm{NaNO}_{3}$ which contains a known amount of lithium nitrate. This mixture was kept at a fixed temperature in a quartz vessel and stirred by a stainless steel stirrer. During the adsorption experiment, the lithium ion concentration in the supernatant was determined by flame spectrochemical analysis (Instrumentation Laboratory Inc. AA/ AE Spectrophotometers Model IL551). The lithium ion uptake by activated alumina was evaluated from the decrease in the lithium ion concentration in molten salt.

\section{Results and discussion}

\subsection{Physical properties of activated alumina}

3.1.1 DTA-TG curves and X-ray diffraction patterns

Figure 1 shows DTA and TG curves for alumina gel, which was obtained by drying alumina sol at $120^{\circ} \mathrm{C}$ for $24 \mathrm{~h}$ in air, as a function of temperature. Alumina gel exhibited two broad endothermic peaks at 82 and $460^{\circ} \mathrm{C}$ and no exothermic peak up to $1200^{\circ} \mathrm{C}$. The low-temperature peak may be identified as being due to the removal of physically adsorbed or chemisorbed water (loosely bound water), while the high-temperature peak may be due to the transformation of boehmite to $\gamma$-alumina, accompanied by the high loss in weight caused by the release of water molecules or dehydration of hydroxyl groups existing as structural water. It is noted in Fig. 1 that gradual loss in weight occurred over $525^{\circ} \mathrm{C}$, where the transformation from $\gamma$-alumina to $\alpha$-alumina proceeded gradually. This result is consistent with studies previously reported on the transformation from boehmite to $\alpha$-alumina. ${ }^{5)-7)}$ The cumulative weight loss for alumina gel was $26.5 \%$ in this measurement.

In order to examine the phase transformation process of alumina gel in detail, X-ray diffraction analysis was performed. Figure 2 shows the X-ray diffraction patterns of activated alumina samples "a"

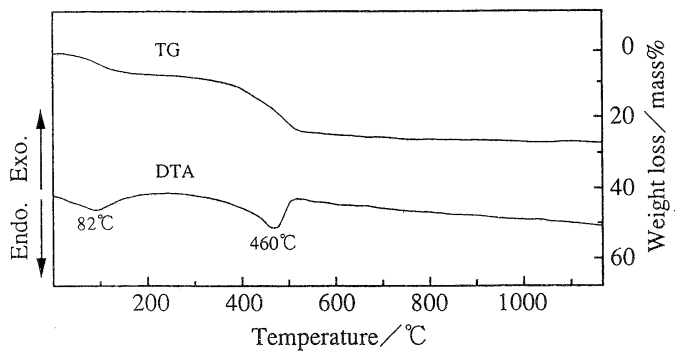

Fig. 1. DTA and TG curves for alumina sol used as a starting material for preparing the activated alumina samples.

Note: Before measurement, alumina sol was dried at $120^{\circ} \mathrm{C}$ for $24 \mathrm{~h}$ in air to form alumina gel.

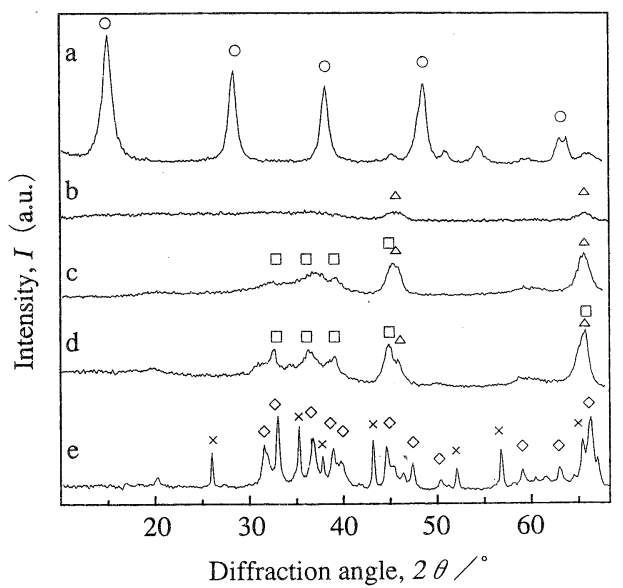

Fig. 2. X-ray diffraction patterns of the activated alumina samples "a" to "e".

$\bigcirc$ : $\gamma$ - $\mathrm{AlO}(\mathrm{OH})$ (Boehmite), $\triangle: \gamma-\mathrm{Al}_{2} \mathrm{O}_{3}, \square: \delta-\mathrm{Al}_{2} \mathrm{O}_{3}, \diamond: \theta-\mathrm{Al}_{2} \mathrm{O}_{3}$, $\times: \alpha-\mathrm{Al}_{2} \mathrm{O}_{3} ; \mathrm{a}: 300^{\circ} \mathrm{C}$, b: $500^{\circ} \mathrm{C}, \mathrm{c}: 700^{\circ} \mathrm{C}, \mathrm{d}: 900^{\circ} \mathrm{C}$, e: $1100^{\circ} \mathrm{C}$ 
to "e". In these samples, the following phases in Eq.

(1) were identified:

$300^{\circ} \mathrm{C}$

boehmite; $\mathrm{AlO}(\mathrm{OH})$

$500^{\circ} \mathrm{C}$

$\rightarrow$ amorphous alumina, slight amount of $\gamma$-alumina $700^{\circ} \mathrm{C}^{\circ}$

$\rightarrow \gamma$-alumina, slight amount of $\delta$-alumina $900^{\circ} \mathrm{C}$

$\rightarrow \delta$-alumina, slight amount of $\gamma$-alumina $1100^{\circ} \mathrm{C}$

$\rightarrow \theta$-alumina , $\alpha$-alumina

It is apparent from Fig. 2 that samples " $b$ " to " $d$ " are less crystalline than sample " $\mathrm{e}$ ". In sample " $\mathrm{e}$ " heat-treated at $1100^{\circ} \mathrm{C}$ for $6 \mathrm{~h}$, two phases of $\theta$-alumina and $\alpha$-alumina coexist, suggesting that it is being converted from $\theta$-alumina to $\alpha$-alumina. ${ }^{8)}$ This observation is in good agreement with previously reported results, ${ }^{5)}{ }^{-7)}$ as well as those of DTA and TG curves.

\subsubsection{Surface properties}

The surface texture of activated alumina was determined from the analysis of nitrogen adsorption isotherms. Figure 3 shows variations in both the specific surface area and pore volume of samples "a" to " $\mathrm{e}$ ".

The specific surface areas are in the range from $50 \times 10^{3}$ to $168 \times 10^{3} \mathrm{~m}^{2} / \mathrm{kg}$ and the specific pore volumes are in the range from $0.220 \times 10^{-3}$ to $0.435 \times 10^{-3} \mathrm{~m}^{3} / \mathrm{kg}$. Both increased steeply from samples "a" to " $b$ ". In sample " $b$ ", the values of surface area and pore volume were the highest. In samples " $b$ " to " $e$ ", both the surface area and the pore volume decreased with the increase of heat treatment temperature from 500 to $\left.1100^{\circ} \mathrm{C} .{ }^{9}\right)$ In particular, the decrease from " $\mathrm{d}$ " to " $\mathrm{e}$ " was steep. It may be caused by the progress of sintering accompanied by the acceleration of crystallization at $1100^{\circ} \mathrm{C}$.

The pore size distributions of samples "a" to "e" are shown in Fig. 4. Table 3 lists the mean pore radii calculated as the weighted average sizes from the pore size distributions. Sample "a", heat-treated at the lowest temperature, $300^{\circ} \mathrm{C}$, exhibited the smallest pore size distribution and the peaks of the

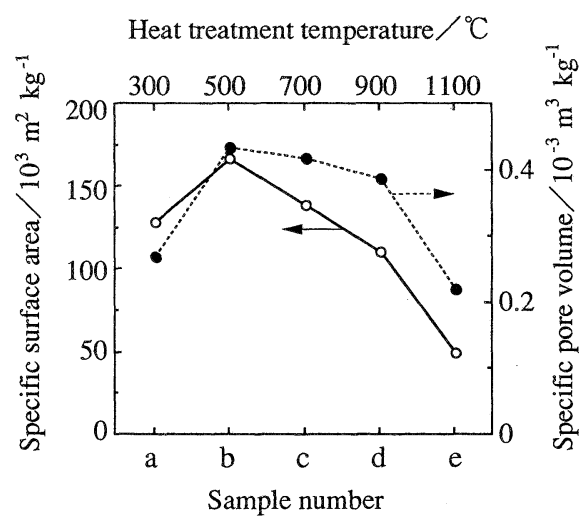

Fig. 3. Specific surface area and pore volume of the activated alumina samples as a function of heat treatment temperature.

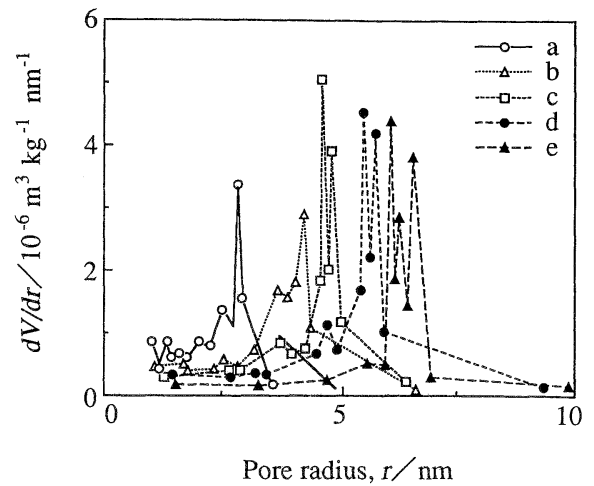

Fig. 4. Pore size distributions of the activated alumina samples heat-treated at different temperatures.

Table 3. Mean Pore Radii of the Activated Alumina Samples Calculated as the Weighted Average Sizes from the Pore Size Distributions

\begin{tabular}{ccc}
\hline $\begin{array}{c}\text { Sample } \\
\text { number }\end{array}$ & $\begin{array}{c}\text { Heat treatment } \\
\text { temperature } \\
/{ }^{\circ} \mathrm{C}\end{array}$ & $\begin{array}{c}\text { Mean pore radius } \\
/ \mathrm{nm}\end{array}$ \\
\hline $\mathrm{a}$ & 300 & 2.1 \\
$\mathrm{~b}$ & 500 & 3.0 \\
$\mathrm{c}$ & 700 & 3.8 \\
$\mathrm{~d}$ & 900 & 4.7 \\
$\mathrm{e}$ & 1100 & 5.9 \\
\hline
\end{tabular}

distribution curves showed a regular shift to larger pore radius from samples "a" to "e" at about $1 \mathrm{~nm}$ intervals. Hence it was found that the pores grew larger in size upon heat treatment at higher temperature. ${ }^{10), 11)}$

\subsection{Adsorption of lithium ions by activated alu- mina}

\subsubsection{Adsorption uptake of lithium ions}

Studies on adsorption of lithium ions by activated alumina were conducted at $453^{\circ} \mathrm{C}$. Activated alumina of $0.04 \mathrm{~kg}$ was added to $440 \mathrm{~cm}^{3}$ molten $\mathrm{NaNO}_{3}$ with a lithium ion concentration of around 100 mass ppm and allowed to stand for $10 \mathrm{~d}$. Molten salt continued to release brown-colored vapor (probably $\mathrm{NO}_{x}$ gases) for the first 10-30 min when activated alumina was added to it. Figure 5 shows the increase of lithium ion uptake by the samples depending on adsorption time. None of the lithium ion adsorption values attained equilibrium until after $10 \mathrm{~d}$. Therefore, it should be noted that the lithium ion uptake data discussed below pertain to nonequilibrium adsorption.

The lithium ion uptake decreased regularly from samples "a" to "e", indicating that lithium ion uptake decreased with the increase of heat treatment temperature from 300 to $1100^{\circ} \mathrm{C}$. This result may be understood well by considering the variation of the surface area of the samples, which is described in detail below.

3.2.2 Changes of physical properties throughout adsorption 


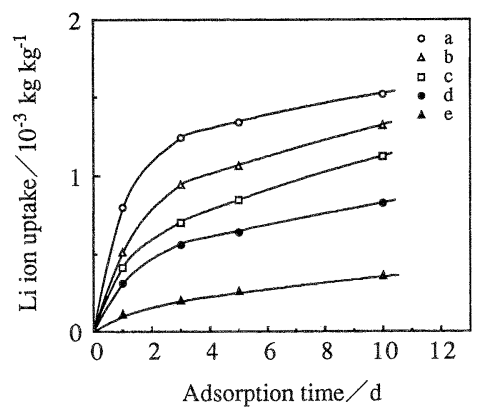

Fig. 5. Lithium ion uptake by the activated alumina samples vs. adsorption time. Weight of activated alumina is $0.04 \mathrm{~kg}$ and initial lithium ion concentration in $\mathrm{NaNO}_{3}$ is around 100 mass ppm. Adsorption time period: $10 \mathrm{~d}$, Adsorption temperature: $453^{\circ} \mathrm{C}$

To examine the changes of physical properties of activated alumina throughout adsorption, first, their surface properties were measured before and after adsorption. Table 4 shows the changes of specific surface area and pore volume throughout adsorption. Their values were almost unchanged throughout adsorption except for sample "a", suggesting that the stability of activated alumina was maintained in molten salt at $453^{\circ} \mathrm{C}$ for $10 \mathrm{~d}$. Since adsorption temperature $\left(453^{\circ} \mathrm{C}\right)$ was higher than heat treatment temperature $\left(300^{\circ} \mathrm{C}\right)$ of sample "a" , the transformation from boehmite to amorphous alumina proceeded during adsorption, as confirmed by the Xray diffraction pattern shown in Fig. 6 . As the result of the transformation accompanied by dehydration and release of water, it is considered that both the surface area and the pore volume increased in the case of sample "a".

Furthermore, as shown in Fig. 7, a graphical comparison of pore size distributions was made for sample "a" for before and after adsorption. Figure 7 distinctly shows that distribution shifted to larger pore radius after adsorption, indicating that the pores were widened by the release of water molecules or the dehydration of hydroxyl groups at adsorption temperature. ${ }^{7), 10), 11)}$ Additionally, the mean pore radius, as the weighted average size, changed from 2.1 to $2.5 \mathrm{~nm}$, which was still smaller than $3.0 \mathrm{~nm}$ of sample "b".

Table 4. Changes of Both the Specific Surface Areas and Pore Volumes throughout Adsorption for the Activated Alumina Samples

\begin{tabular}{|c|c|c|c|c|}
\hline \multirow{2}{*}{$\begin{array}{l}\text { Sample } \\
\text { number }\end{array}$} & \multicolumn{2}{|c|}{$\begin{array}{l}\text { Specific surface area } \\
\qquad / 10^{3} \mathrm{~m}^{2} \mathrm{~kg}^{-1}\end{array}$} & \multicolumn{2}{|c|}{$\begin{array}{l}\text { Specific pore volume } \\
\qquad / 10^{-3} \mathrm{~m}^{3} \mathrm{~kg}^{-1}\end{array}$} \\
\hline & $\begin{array}{l}\text { Before } \\
\text { adsorption }\end{array}$ & $\begin{array}{l}\text { After } \\
\text { adsorption }\end{array}$ & $\begin{array}{l}\text { Before } \\
\text { adsorption }\end{array}$ & $\begin{array}{l}\text { After } \\
\text { adsorption }\end{array}$ \\
\hline a & 128 & 166 & 0.270 & 0.377 \\
\hline b & 168 & 166 & 0.435 & 0.406 \\
\hline c & 139 & 132 & 0.418 & 0.420 \\
\hline d & 111 & 112 & 0.387 & 0.382 \\
\hline $\mathrm{e}$ & 50 & 49 & 0.220 & 0.226 \\
\hline
\end{tabular}

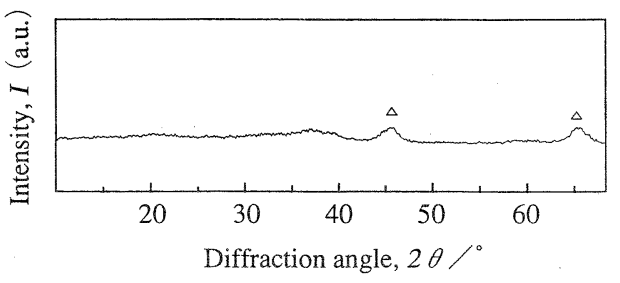

Fig. 6. X-ray diffraction pattern of sample "a" after adsorption. $\triangle: \gamma-\mathrm{Al}_{2} \mathrm{O}_{3}$

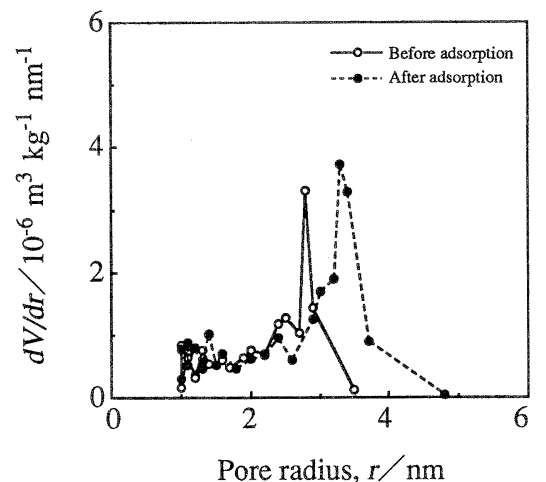

Fig. 7. Change of the pore size distribution throughout adsorption for sample "a".

\subsection{Relationship between physical properties} and adsorptive capabilities

By comparison of the different phases of activated alumina shown in Fig. 2 or Fig. 6 with the results of lithium ion uptake shown in Fig. 5, it was first confirmed that amorphous alumina of both sample "a" and " $b$ " had higher adsorptive capabilities for lithium ions in molten salt than any other crystalline phases. This agrees well with the result for selective adsorption of lithium ions from seawater by hydrous aluminum oxide. ${ }^{12)}$ Thus, the surface microstructure of amorphous alumina may be suitable for adsorption of lithium ions regardless of whether it is in solution or in molten salt.

In this case, however, there was a difference in lithium ion uptake between samples "a" and " $b$ ", although the states of the two samples were the same amorphous phase after adsorption. We infer that the surface of sample "a" was activated during the phase transformation accompanied by the increase of the surface area, resulting in the accelerated adsorption of lithium ions.

Secondly, the relationship between the surface area and the lithium ion uptake of activated alumina was evaluated. As expected, it was observed that activated alumina with larger surface area possessed higher lithium ion uptake through the comparison of Fig. 5 and Table 4. Moreover, the lithium ion uptake per unit surface area of activated alumina was calculated. Figure 8 shows the change of the lithium ion uptake per unit surface area with heat treatment temperature together with that of the lithium ion uptake itself. For sample "a", the surface area after adsorption was used for the calculation. From this figure, it 


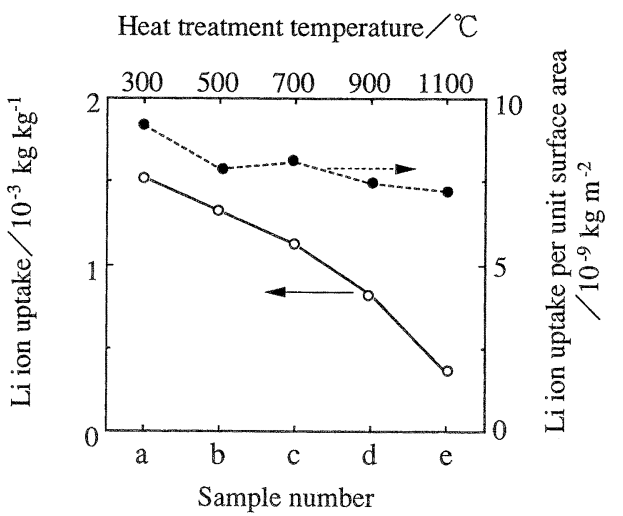

Fig. 8. Lithium ion uptake and lithium ion uptake per unit surface area on the activated alumina samples as a function of heat treatment temperature.

Adsorption time period: $10 \mathrm{~d}$, Adsorption temperature: $453^{\circ} \mathrm{C}$

was recognized that the lithium ion uptake per unit surface area depends on heat treatment temperature or the phase of activated alumina, although the degree of change is small compared with the sharp decline of the lithium ion uptake. Consequently, it is concluded that the surface microstructure of each activated alumina has a different adsorptive capability for lithium ions. However, it is clear that we must choose activated alumina with as large a surface area as possible to attain high uptake of lithium ions.

Thirdly, we evaluated the relationship between the pore size distribution and the lithium ion uptake of activated alumina. Judging from the comparison of Fig. 4 and Fig. 5, the lithium ion uptake decreased with increasing pore size. It should be emphasized, however, that the pore size of every activated alumina is much larger than the ionic radius of lithium $(0.06 \mathrm{~nm})$. As listed in Table 3 , even the mean pore radius of sample "a", which had the smallest pore size distribution, is more than forty times larger than the ionic radius of lithium. Therefore, it is considered that there is little effect of the pore size on the adsorptive capabilities for lithium ions. It is satisfactory to consider that the phase, the state (amorphous or crystalline) or the surface microstructure of activated alumina is much more closely related to the adsorptive capabilities than the pore size.

Lastly, the author points out a key issue for using this adsorption technique as a practical production method. From the industrial standpoint, one of the biggest future problems is recycling or repetitive use of activated alumina, although many other problems have not yet been solved. In order to reduce the cost of purification of molten salt further, a lithium adsorption-elution cycle using activated alumina should be developed.

\section{Conclusions}

(1) Studies have been performed on the relationship between physical properties and adsorptive capabilities of activated alumina for lithium ions.
(2) The activated alumina samples were prepared by heat treatment of commercially available alumina sol at different temperatures.

(3) The specific surface areas and specific pore volumes of the samples changed in the ranges from $50 \times 10^{3}$ to $168 \times 10^{3} \mathrm{~m}^{2} / \mathrm{kg}$ and from $0.220 \times 10^{-3}$ to $0.435 \times 10^{-3} \mathrm{~m}^{3} / \mathrm{kg}$, respectively, and the phase transformation from boehmite to $\alpha$-alumina occurred through the phases of amorphous, $\gamma$-, $\delta$-, and $\theta$-alumina upon heat treatment.

(4) It was confirmed from the changes of physical properties throughout adsorption that the stability was maintained in molten salt, except for the sample heat-treated at $300^{\circ} \mathrm{C}$, which turned from boehmite to amorphous alumina during adsorption at $453^{\circ} \mathrm{C}$

(5) Amorphous alumina showed higher adsorptive capabilities for lithium ions in molten $\mathrm{NaNO}_{3}$ than any other phase of activated alumina, suggesting that its surface microstructure is suitable for adsorption of lithium ions.

(6) The adsorption uptake of lithium ions increased in proportion to the surface area of activated alumina.

(7) Since the lithium ion uptake per unit surface area varied with the phase of alumina, it may be concluded that the surface microstructure of each activated alumina has a different adsorptive capability for lithium ions.

(8) There is little effect of the pore size on adsorptive capabilities for lithium ions. This is evidenced by the fact that the mean pore radius of each activated alumina sample was at least forty times larger than the ionic radius of lithium.

Acknowledgment The author is grateful to Dr. T . Yamagishi of Nippon Glass Fiber Co., Ltd. for his constant support and helpful advice. He also appreciates Dr. I. Kitano of Technical Research Laboratory, Nippon Sheet Glass Co., Ltd. for his encouragement and helpful advice. Furthermore, he would like to thank the staff of the Optics and Analysis Groups of his company for their support and valuable discussion.

\section{References}

1) Y. Ogura, Kogaku (Jpn. J. Opt.), 10, 111-17 (1981).

2) M. Toyama and M. Takami, Appl. Opt., 21, 1013-16 (1982).

3) K. Fujii, J. Ceram. Soc. Japan, 102, 902-07 (1994).

4) E. P. Barret, L. G. Joyner and P. P Halenda, J. Am. Chem. Soc., 73, 373-80 (1951).

5) K. Sakamoto, Yogyo-Kyokai-Shi, 67, 114-25 (1959).

6) R. K. Iler, J. Am. Ceram. Soc., 44, 618-24 (1961).

7) G. V. Rama Rao, S. Venkadesan and V. Saraswati, J. NonCryst. Solids, 111, 103-12 (1989).

8) K. Hayashi, S. Toyoda, H. Takebe and K. Morinaga, Seramikkusu Ronbunshi, 99, 550-55 (1991).

9) A. S. Russell and C. N. Cochran, Ind. Eng. Chem., 42, 133640 (1950).

10) J. H. De Boer and B. C. Lippens, J. Catal., 3, 38-43 (1964).

11) B. C. Lippens and J. H. De Boer, J. Catal., 3, 44-49 (1964).

12) T. Kitamura and H. Wada, Nippon Kaisui Gakkaishi, 32, 78-81 (1978). 